\title{
Impact of Labor Induction at 39 Weeks Gestation Compared with Expectant Management on Maternal and Perinatal Morbidity among a Cohort of Low-risk Women
}

\author{
Sabrina C. Burn ( $\nabla$ burn@umn.edu ) \\ University of Minnesota \\ Ruofan Yao \\ Loma Linda University School of Medicine \\ Maria Diaz \\ Loma Linda University School of Medicine \\ Jordan Rossi \\ Loma Linda University School of Medicine \\ Stephen Contag \\ University of Minnesota
}

\section{Research Article}

Keywords: induction of labor (IOL), maternal and perinatal outcomes, Relative risks (aRR), spontaneous onset of labor (SOL)

Posted Date: March 15th, 2021

DOl: https://doi.org/10.21203/rs.3.rs-289350/v1

License: (c) (i) This work is licensed under a Creative Commons Attribution 4.0 International License.

Read Full License

Version of Record: A version of this preprint was published at The Journal of Maternal-Fetal \& Neonatal Medicine on December 29th, 2021. See the published version at https://doi.org/10.1080/14767058.2021.2021396. 


\section{Abstract}

Objective: To determine rates of maternal and perinatal outcomes after induction of labor (IOL) at 39 weeks compared with expectant management.

Methods: Cohort study of low risk women delivered between 39-42 weeks from 2015 to 2018 . We excluded births with fetal abnormalities, previous cesarean, multiple pregnancies or those with spontaneous onset of labor (SOL) or indicated delivery at 39 weeks. Data was abstracted from National Center for Health Statistics birth files. Relative risks (aRR) were estimated with multivariable log-binomial regression.

Main Outcome Measures: Maternal outcomes: chorioamnionitis (Triple I), blood transfusion, neonatal intensive care unit (NICU) admission, uterine rupture, cesarean delivery and cesarean hysterectomy. Fetal and infant outcomes: fetal death, 5-minute Apgar $\leq 3$, prolonged ventilation, seizures, ICU admission, and death within 28 days.

Results: There were 15,900,956 births, with 8,540,063 after exclusions. The IOL group included 1,177,790 births excluding women with diabetes or hypertensive disease. There were 3,835,185 births after 39 weeks excluding women with diabetes or chronic hypertension. With IOL at 39 weeks the risk for blood transfusion (p-value < 0.01; aRR 0.78; 95\% Cl [0.75-0.82]), Triple I (p-value < 0.01; aRR 0.71; $95 \% \mathrm{Cl}$ [0.70$0.73]$ ) and cesarean delivery ( $\mathrm{p}$-value $<0.01$; aRR $0.87 ; 95 \% \mathrm{Cl}$ [0.87-0.88]) were lower, albeit increased risk of cesarean hysterectomy (p-value $<0.01$; aRR 1.23; $95 \% \mathrm{Cl}$ [1.07-1.41]). Neonates had a lower risk for 5minute Apgar $\leq 3$ ( $p$-value < 0.01; aRR 0.68; $95 \% \mathrm{Cl}[0.66-0.71]$ ), prolonged ventilation ( $p$-value < 0.01; aRR $0.84 ; 95 \% \mathrm{Cl}[0.81-0.87]$ ), NICU admission (p-value < 0.01; aRR 0.86; 95\% Cl [0.85-0.87]), and neonatal seizures ( $p$-value $<0.01$; aRR $0.85 ; 95 \% \mathrm{Cl}[0.76-0.96]$ ). There was no difference in risk for neonatal death $0.99 \%$ (p-value 0.99; aRR 1.00; 95\% Cl [0.99-1.00]), or fetal death ( $p$-value 0.78 ; aRR 1.0002; 95\% Cl [0.991.002]. This benefit was greater compared with each subsequent week.

Conclusions: Induction of labor at 39 weeks of gestation in a low risk cohort is associated a lower risk of cesarean delivery, transfusions and infection, as well as lower neonatal morbidity, without difference in fetal or neonatal death. This appears to be associated with increased risk for cesarean hysterectomy.

\section{Introduction}

Decisions regarding the timing for induction of labor (IOL) take into consideration both maternal and perinatal risks. Retrospective cohort studies have reported an increase in the frequency of cesarean deliveries associated with IOL when comparing women undergoing IOL with women having spontaneous onset of labor (SOL) at term ${ }^{1,2}$. Subsequent observational and retrospective cohort studies found that women who underwent IOL prior to 41 weeks of gestation had an increased frequency of operative vaginal deliveries and an increased risk for adverse neonatal outcomes and neonatal intensive care (NICU) admissions ${ }^{3-8}$. These led to recommendations to avoid elective IOL among low risk women and 
traditionally expectant management was seen as an effective strategy to decrease cesarean delivery rates in the population.

Subsequent retrospective cohort studies reported longer a duration of labor but similar cesarean delivery and adverse neonatal outcome rates among nulliparous women with a favorable cervix undergoing elective IOL compared with those managed expectantly ${ }^{9}$. A larger population based cohort study reported decreased perinatal mortality with increased rates of admission to NICU without differences in cesarean delivery rates after term elective IOL in an unselected population ${ }^{10}$. Data from the National Center for Health Statistics (NCHS) from 2005 reported improved neonatal outcomes with a decrease in cesarean delivery rates among low risk nulliparous women having IOL at 39 weeks compared with expectant management ${ }^{11}$. This was also observed in a subsequent population based study using data from the State of California from 2006 that compared IOL among non-anomalous singleton pregnancies with expectant management for each week of gestation between 37 and 42 weeks. That study found the risk for cesarean delivery and adverse neonatal outcomes was decreased with IOL compared with expectant management. Prior to 39 weeks, there was an increased rate of neonatal hyperbilirubinemia ${ }^{12}$. There have been several meta-analyses of randomized controlled trials (RCT) reporting that IOL at term was associated with lower cesarean delivery rates as well as an improvement in neonatal outcomes, which is significant among term and post term pregnancies, but not among preterm deliveries ${ }^{13-16}$. All of these meta-analyses included women with singleton pregnancies undergoing IOL at 39 weeks but did not always specify the presence of maternal comorbidities or parity. Only one of these reported on a significant reduction on fetal death rate but did not specify whether maternal comorbidities were present ${ }^{13}$. The most recent meta-analyses included nulliparous low risk women and reported a reduction in cesarean delivery, perinatal mortality and morbidity with IOL at 39 weeks, compared with expectant management ${ }^{14}$. In the most recent meta-analysis, the overall findings were consistent with previous reports that show a clear reduction in cesarean deliveries, perinatal morbidity and mortality with a policy of labor induction at or beyond 37 weeks compared with expectant management. It also raised questions regarding risk profiles, whether IOL at 39 weeks is better than elective IOL at 40 or 41 weeks and recommends further research into women's values and preferences. No evidence for adverse effects were found for a policy of elective induction in any of these studies ${ }^{15}$.

The meta-analyses performed after 2018 reported similar results but were heavily influenced by the ARRIVE trial supporting elective IOL at 39 weeks for low risk nulliparous women ${ }^{16-18}$. These findings have led to a formal statement from the Society of Maternal Fetal Medicine stating that it is reasonable to offer elective IOL to low risk nulliparous women at 39 weeks 0 days of gestation or beyond, although further research is still required ${ }^{19}$. The impact of a policy of IOL at 39 weeks with a decrease in cesarean delivery rates supports this practice within a cohort of low risk nulliparous women with a singleton pregnancy. This policy excludes women with preexisting conditions or comorbidities such as prior cesarean delivery, where recent evidence showed that elective IOL among women with one prior cesarean delivery had improved neonatal outcomes but increased cesarean delivery rates ${ }^{20}$. 
The results from the Walker et al. and the ARRIVE trial, do not provide definitive evidence of potential advantages or disadvantages of labor induction at 39 weeks versus expectant management outside of a clinical trial ${ }^{17,21}$. Yet these recommendations are presumably adopted in a broad variety of clinical settings.

It is with these previously published findings in mind, that we designed the current population based retrospective cohort study that includes all clinical settings, and which analyzed a low risk birth cohort delivered prior to the publication of the ARRIVE trial ${ }^{17}$. Our hypothesis is that IOL in a contemporary low risk cohort at 39 weeks, outside of a clinical research setting, is associated with a decreased rate of cesarean deliveries and improvement in perinatal outcomes compared with women managed expectantly up to 42 weeks.

\section{Methods}

This is a national retrospective cohort analysis using data abstracted from the NCHS and Centers for Disease Control and Prevention's (CDC) Division of Vital Statistics database from 2015 to $2018{ }^{22}$. We chose the most recent 4 years of livebirth and fetal death data available. These years reflect outcomes prior to the formal recommendations regarding elective IOL at 39 weeks ${ }^{19}$. The data is publicly available and de-identified, therefore institutional review board approval was not required.

The intervention group consisted of all women undergoing IOL at 39 weeks of gestation without an identifiable medical indication, irrespective of their final mode of delivery. The expectant management group consisted of women delivered between 40 and 42 weeks of gestation. Weeks were stated as completed weeks of gestation, which is how this variable is reported in the fetal death or live birth databases.

We excluded all women at less than 39 weeks or greater than 42 weeks of gestation, multifetal gestations, known fetal congenital anomalies or aneuploidy, with previous cesarean delivery, and infant deaths at greater than 28 days. These were excluded from analysis because of their association with postnatal complications often unrelated to the birth process ${ }^{23,24}$. Deliveries $>42$ weeks gestation were excluded primarily because it is no longer common practice to continue expectant management at this gestational age given the inherent neonatal morbidities associated with post-date delivery ${ }^{25,26}$. Women with any form of diabetes or hypertension were excluded from the intervention group to isolate the effects of induction of labor at 39 weeks in a low risk cohort compared with expectant management in an otherwise low-risk population. These conditions are considered high-risk conditions with delivery recommended by 39 weeks ${ }^{23-26}$. Gestational hypertensive disorders can present after 39 weeks but were excluded if diagnosed in the 39th week, as delivery is recommended by 37 weeks or at time of diagnosis 24. As such, expectant management would not be a reasonable option if the diagnosis was made in the 39th week, but would have been an option had they been diagnosed after 39 weeks, which is possible due to its incidence with advancing gestational age ${ }^{17,27}$. 
The fetal death database was merged with the livebirth database. There are variables that are included in the livebirth but not in the fetal death certificates. These include fetal congenital anomalies or aneuploidies, maternal puerperal infection, blood transfusion and cesarean hysterectomy. No imputations were performed and their absence is expected to produce an underestimate in the incidence of those outcomes.

We included all fetal deaths from 40 to 42 weeks, but only intrapartum at 39 weeks ${ }^{22}$. We were able to identify this group by verifying when the diagnosis was made, whether it was pre-labor, intrapartum, or unknown. This variable is reported in all except for the following jurisdictions: District of Columbia, Hawaii, Kansas, Missouri, Montana, Nevada, and New York.

Maternal demographic information was compared between the two management groups using the appropriate univariate statistical test. The maternal outcomes of interest included: cesarean delivery, intra-amniotic infection or inflammation (triple I), blood transfusion, intensive care unit (ICU) admission, uterine rupture, and cesarean hysterectomy. Triple I, or chorioamnionitis as it was previously known. The neonatal outcomes of interest included: fetal death, 5-minute Apgar score $\leq 3$, assisted ventilation for $>6$ hours, NICU admission, seizure, and neonatal death $<28$ days of life.

Multivariable log-binomial regression analysis was performed to calculate adjusted relative risk (aRR) to control for potential confounding variables based on historic significance and univariate analysis. These variables had to be included in both the certificate of live birth and fetal death and included maternal age, race, parity, education, prenatal care, cigarette use, and body mass index (BMI). Backward stepwise elimination method was performed to arrive at the final regression model, which included maternal education, ethnicity, parity, BMI and cigarette use. A secondary analysis reported frequencies for cesarean delivery, fetal and neonatal death, and seizures, in addition to calculating the relative risk for each subsequent week.

We chose to calculate the relative risk (RR), which is usually the parameter of interest in cohort studies especially since odds ratios can overestimate risk for more common outcomes and overestimation of the importance of a risk factor may lead to intervention errors ${ }^{28}$. Statistical significance was defined as $p$ value $<0.01$. Power analysis was not performed as the sample size included the entire population. All analyses were performed using Stata 14 statistical software (College Station, TX) ${ }^{28}$ and we adhered to "Strengthening the Reporting of Observational Studies" (STROBE) guidelines for reporting cohort studies 29.

\section{Results}

After exclusions, there were 5,017,524 births with 5,012,975 livebirths, 2,179 livebirths followed by neonatal death and 2,370 fetal deaths available for review. There were 1,177,790 low risk, singleton women, without a history of cesarean delivery, with non-anomalous pregnancies in the 39-week IOL or intervention group. This included 520 cases with neonatal death and 120 intrapartum fetal deaths. 
Among those managed expectantly, there were $3,835,185$ births, of which there were 1,659 subsequent neonatal deaths, and 2,250 fetal deaths (Fig. 1).

Maternal descriptive characteristics were similar between the two groups and summarized in Table 1. In both groups, the mean maternal age was 28.0 years; the most common ethnicity among women was White followed by Black; the majority had a high school or greater level of education and the mean body mass index (BMI) was $26 \mathrm{~kg} / \mathrm{m} 2$ in both groups with approximately $5 \%$ of women reported as morbidly obese. Median parity was one in the IOL and zero in the expectantly managed group. Approximately one third of women in the IOL and over half of the women in the expectantly managed group had a prior vaginal delivery. 
Table 1

Maternal descriptive information for the low risk intervention group and the expectant management group

\begin{tabular}{|c|c|c|}
\hline Variable & IOL at 39 weeks & Expectant Management \\
\hline \multicolumn{3}{|l|}{ Age } \\
\hline Maternal age (mean, s.d.) & $28.2(5.9)$ & $28.1(5.6)$ \\
\hline Advanced maternal age $(n, \%)$ & $199,666(16.9)$ & $582,545(15.2)$ \\
\hline \multicolumn{3}{|l|}{ Race } \\
\hline White (n, \%) & $942,786(80.0)$ & $2,998,521(78.1)$ \\
\hline Black (n, \%) & $167,077(14.2)$ & $540,296(14.1)$ \\
\hline Hispanic (n, \%) & $11,678(1.0)$ & $38,724(1.0)$ \\
\hline Other (n, \%) & $56889(4.8)$ & $261,553(6.8)$ \\
\hline \multicolumn{3}{|l|}{ Education } \\
\hline High school diploma (n, \%) & $307,971(26.1)$ & $895,059(23.3)$ \\
\hline College or greater $(n, \%)$ & $703,569(59.7)$ & $2,391,901(62.3)$ \\
\hline High school incomplete (n, \%) & $166,890(14.2)$ & $552,134(14.4)$ \\
\hline \multicolumn{3}{|l|}{ BMI } \\
\hline BMI (mean, s.d.) & $26.8(6.5)$ & $26.1(6.0)$ \\
\hline BMI 30-39.9 kg/m2 (n, \%) & $247,102(21.0)$ & $688,343(17.9)$ \\
\hline $\mathrm{BMI} \geq 40$ kg/m2 (n, \%) & $69,400(5.9)$ & $216,136(5.6)$ \\
\hline Tobacco in pregnancy $(n, \%)$ & $108,881(9.2)$ & $232,824(6.1)$ \\
\hline Parity (median, IQR) & $1[0-2]$ & $0[0-1]$ \\
\hline Previous vaginal birth (n, \%) & $415,323(35.2)$ & $2,038,975(53.1)$ \\
\hline \multicolumn{3}{|l|}{ s.d.: standard deviation } \\
\hline \multicolumn{3}{|l|}{ IQR: Interquartile range } \\
\hline $\mathrm{n}=$ number & & \\
\hline
\end{tabular}

Approximately $35 \%$ of women managed expectantly underwent IOL for various indications while $65 \%$ had SOL. We observed an incidence of gestational hypertensive disease of $3 \%$ after 39 weeks. The relative risk for maternal morbidity was calculated by comparing the risk of IOL at 39 weeks to the using the risk for those managed expectantly as the reference value. The relative risks were adjusted for maternal education, ethnicity, parity, BMI and cigarette use. Women were significantly less likely to be diagnosed 
with any of the maternal outcomes analyzed after elective IOL at 39 weeks when compared to the expectant management group (Table 2). Although there was no difference in uterine rupture rate, or ICU admission between groups, the risk for a cesarean hysterectomy was unexpectedly increased in the IOL group. The most common adverse outcomes for the entire cohort were cesarean delivery and Triple I. The rate of cesarean delivery in the elective IOL group was $13 \%$ lower than in the expectantly managed group after adjusted analysis. Elective IOL at 39 weeks was also associated with a $30 \%$ reduction in risk for puerperal infection compared with expectant management after risk adjustment.

Table 2

Maternal outcomes for induction of labor at 39 weeks compared with expectant management

\begin{tabular}{|c|c|c|c|c|c|c|}
\hline \multirow[t]{2}{*}{ Outcomes } & \multirow{2}{*}{$\begin{array}{l}\text { Induction of labor at } \\
39 \text { weeks } \\
\text { N (\%) }\end{array}$} & \multirow{2}{*}{$\begin{array}{l}\text { Expectant } \\
\text { management } \\
\text { (reference } \\
\text { group) } \\
\mathrm{N}(\%)\end{array}$} & \multicolumn{4}{|l|}{ Relative risk } \\
\hline & & & Unadjusted & $\begin{array}{l}\text { Adjusted } \\
\text { a }\end{array}$ & $\begin{array}{l}95 \% \\
\mathrm{Cl}\end{array}$ & $\begin{array}{l}\mathrm{P}- \\
\text { value }\end{array}$ \\
\hline $\begin{array}{l}\text { Cesarean } \\
\text { delivery }\end{array}$ & $145,974(12.39)$ & $\begin{array}{l}686,103 \\
(17.87)\end{array}$ & 0.69 & 0.87 & $\begin{array}{l}0.87- \\
0.88\end{array}$ & $\begin{array}{l}< \\
0.01\end{array}$ \\
\hline $\begin{array}{l}\text { Blood } \\
\text { transfusion }\end{array}$ & $3,155(0.27)$ & $10,780(0.28)$ & 0.72 & 0.78 & $\begin{array}{l}0.75- \\
0.82\end{array}$ & $\dot{0.01}$ \\
\hline Triple I & $15,072(1.28)$ & $93,633(2.44)$ & 0.52 & 0.71 & $\begin{array}{l}0.70- \\
0.73\end{array}$ & $<.01$ \\
\hline $\begin{array}{l}\text { ICU } \\
\text { admission }\end{array}$ & $837(0.07)$ & $2,866(0.07)$ & 0.95 & 1.03 & $\begin{array}{l}0.95- \\
1.12\end{array}$ & 0.44 \\
\hline $\begin{array}{l}\text { Uterine } \\
\text { rupture }\end{array}$ & $164(0.01)$ & $441(0.01)$ & 1.21 & 1.12 & $\begin{array}{l}0.94- \\
1.35\end{array}$ & 0.21 \\
\hline $\begin{array}{l}\text { C- } \\
\text { hysterectomy }\end{array}$ & $299(0.03)$ & $745(0.02)$ & 1.31 & 1.23 & $\begin{array}{l}1.07- \\
1.41\end{array}$ & $<.01$ \\
\hline \multicolumn{7}{|c|}{$\begin{array}{l}\text { a: Adjusted for maternal education greater less than high school, minority race, nulliparous status, } \\
\text { body mass index less than } 18 \text { or greater than } 25 \mathrm{~kg} / \mathrm{m} 2 \text { or smoking in the second and third } \\
\text { trimesters. }\end{array}$} \\
\hline \multicolumn{7}{|c|}{ ICU: Intensive care unit } \\
\hline \multicolumn{7}{|c|}{ Triple I: Intrauterine infection or inflammation } \\
\hline \multicolumn{7}{|c|}{ C-hysterectomy: cesarean hysterectomy } \\
\hline
\end{tabular}

Fetal and neonatal morbidity and mortality were evaluated by comparing the risk among those managed expectantly with infants delivered after elective IOL at 39 weeks using the expectantly managed cases as the reference (Table 3). Neonates in the IOL group were 30\% less likely to have 5 min Apgar $\leq 3$, over 15\% less likely to require prolonged, necessitate NICU admission, or neonatal seizures when compared with 
the expectant management group. There was no difference in the frequency or relative risk of neonatal or fetal death between the two groups (P-value 0.04). When we compared the frequency and relative risk at each week of gestation compared with the risk of elective IOL at 39 weeks, we found a gradual increase from 40 to 42 weeks in the risk for cesarean delivery as well as for neonatal seizures, but no difference in the risk for fetal or neonatal death (Table 4).

Table 3

Neonatal outcomes for induction of labor at 39 weeks compared with expectant management

\begin{tabular}{|c|c|c|c|c|c|c|}
\hline \multirow[t]{3}{*}{ Outcomes } & \multirow{3}{*}{$\begin{array}{l}\text { Induction of } \\
\text { labor at } 39 \\
\text { weeks } \\
\text { N (\%) }\end{array}$} & \multirow{3}{*}{$\begin{array}{l}\text { Expectant } \\
\text { management } \\
\text { (reference } \\
\text { group) } \\
\mathrm{N}(\%)\end{array}$} & \multicolumn{4}{|l|}{ Relative risk } \\
\hline & & & & & & \\
\hline & & & Unadjusted & $\begin{array}{l}\text { Adjusted } \\
\text { a }\end{array}$ & $95 \% \mathrm{Cl}$ & $\begin{array}{l}\mathrm{P}- \\
\text { value }\end{array}$ \\
\hline Fetal death & $120(0.01)$ & $2,250(0.06)$ & 1.0005 & 1.0002 & $\begin{array}{l}0.99- \\
1.002\end{array}$ & 0.78 \\
\hline $\begin{array}{l}5 \text { min } \\
\text { Apgar } \leq 3\end{array}$ & $2,456(0.21)$ & $11,793(0.31)$ & 0.60 & 0.68 & $\begin{array}{l}0.66- \\
0.71\end{array}$ & $\dot{0.01}$ \\
\hline $\begin{array}{l}\text { Prolonged } \\
\text { ventilation }\end{array}$ & $3,438(0.30)$ & $15,586(0.41)$ & 0.73 & 0.84 & $\begin{array}{l}0.81- \\
0.87\end{array}$ & $\begin{array}{l}< \\
0.01\end{array}$ \\
\hline NICU & $33,401(2.90)$ & $\begin{array}{l}148,391 \\
(3.89)\end{array}$ & 0.74 & 0.86 & $\begin{array}{l}0.85- \\
0.87\end{array}$ & $\begin{array}{l}< \\
0.01\end{array}$ \\
\hline Seizure & $296(0.03)$ & $1,344(0.04)$ & 0.73 & 0.85 & $\begin{array}{l}0.75- \\
0.96\end{array}$ & $\begin{array}{l}< \\
0.01\end{array}$ \\
\hline Neonatal death & $520(0.04)$ & $1,659(0.04)$ & 1.02 & 1.00 & $\begin{array}{l}0.99- \\
1.00\end{array}$ & 0.99 \\
\hline \multicolumn{7}{|c|}{$\begin{array}{l}\text { a: Adjusted for maternal education greater less than high school, minority race, nulliparous status, } \\
\text { body mass index less than } 18 \text { or greater than } 25 \mathrm{~kg} / \mathrm{m} 2 \text { or smoking in the second and third } \\
\text { trimesters. }\end{array}$} \\
\hline \multicolumn{7}{|c|}{ NICU: Neonatal intensive care unit } \\
\hline
\end{tabular}


Table 4

Severe maternal and neonatal outcomes at each week from 39 to 40 weeks with the relative risk for severe maternal and neonatal outcomes at each week compared with induction of labor at 39 weeks.

\begin{tabular}{|c|c|c|c|c|c|c|c|}
\hline \multirow[t]{2}{*}{ Outcomes } & \multirow{2}{*}{$\begin{array}{l}\begin{array}{l}39 \\
\text { weeks }\end{array} \\
\mathrm{N}(\%)\end{array}$} & \multicolumn{2}{|l|}{40 weeks } & \multicolumn{2}{|l|}{41 weeks } & \multicolumn{2}{|c|}{42 weeks } \\
\hline & & $N(\%)$ & $\begin{array}{l}\text { aRR }^{a} \\
(95 \% \mathrm{Cl})\end{array}$ & $N(\%)$ & $\begin{array}{l}\text { aRR }^{a} \\
(95 \% \mathrm{Cl})\end{array}$ & $\mathbf{N}(\%)$ & $\begin{array}{l}\text { aRR }^{a} \\
(95 \% \mathrm{Cl})\end{array}$ \\
\hline $\begin{array}{l}\text { Fetal } \\
\text { death }\end{array}$ & $\begin{array}{l}120 \\
(0.01)\end{array}$ & $\begin{array}{l}1,660 \\
(0.06)\end{array}$ & $\begin{array}{l}1.00 \\
(0.99- \\
1.003)\end{array}$ & $\begin{array}{l}500 \\
(0.05)\end{array}$ & $\begin{array}{l}1.00(0.99 \\
\text { to } 1.004)\end{array}$ & $\begin{array}{l}90 \\
(0.20)\end{array}$ & $\begin{array}{l}1.00(0.98 \\
\text { to } 1.01)\end{array}$ \\
\hline Seizure & $\begin{array}{l}296 \\
(0.03)\end{array}$ & $\begin{array}{l}880 \\
(0.03)\end{array}$ & $\begin{array}{l}1.11(0.85 \\
\text { to } 1.45)\end{array}$ & $\begin{array}{l}421 \\
(0.05)\end{array}$ & $\begin{array}{l}2.08(1.54 \\
\text { to } 2.83)\end{array}$ & $\begin{array}{l}14 \\
(0.07)\end{array}$ & $\begin{array}{l}9.56(5.01 \\
\text { to } 18.22)\end{array}$ \\
\hline $\begin{array}{l}\text { Neonatal } \\
\text { death }\end{array}$ & $\begin{array}{l}520 \\
(0.04)\end{array}$ & $\begin{array}{l}1,160 \\
(0.04)\end{array}$ & $\begin{array}{l}1.00(0.99 \\
\text { to } 1.003)\end{array}$ & $\begin{array}{l}434 \\
(0.05)\end{array}$ & $\begin{array}{l}1.00(0.99 \\
\text { to } 1.004)\end{array}$ & $\begin{array}{l}43 \\
(0.10)\end{array}$ & $\begin{array}{l}1.00(1.00 \\
\text { to } 1.00)\end{array}$ \\
\hline $\begin{array}{l}\text { Cesarean } \\
\text { delivery }\end{array}$ & $\begin{array}{l}145,974 \\
(12.39)\end{array}$ & $\begin{array}{l}471,469 \\
(16.35)\end{array}$ & $\begin{array}{l}1.17(1.16 \\
\text { to } 1.19)\end{array}$ & $\begin{array}{l}203,689 \\
(22.35)\end{array}$ & $\begin{array}{l}1.70(1.67 \\
\text { to } 1.72\end{array}$ & $\begin{array}{l}10,945 \\
(24.48)\end{array}$ & $\begin{array}{l}2.28(2.19 \\
\text { to } 2.37)\end{array}$ \\
\hline
\end{tabular}

\section{Discussion}

\section{Main Findings}

This retrospective study analyzed data from a cohort of singleton, non-anomalous pregnancies among low-risk women who were delivered within various health care settings across the United States, prior statements published by large national organizations supporting elective IOL at 39 weeks ${ }^{19}$. Our data demonstrated a $13 \%$ reduction in risk for cesarean delivery, and a $30 \%$ reduction in the risk for chorioamnionitis among women who underwent induction of labor at 39 weeks of gestation compared with women managed expectantly past 39 weeks. This small to moderate protective effect was also seen for blood transfusion, cesarean hysterectomy, and ICU admission.

The large National institute of Health $(\mathrm{NIH})$ funded RCT regarding elective induction of labor at 39 weeks included a very specific population of low risk nulliparous women ${ }^{17}$. Although ours is a retrospective cohort study, it reflects a large national cohort analyzed over the course of 4 years prior to the publication of the trial results. The population included was not limited to low risk nulliparous women being delivered at large academic medical centers under a strict trial protocol, but considered all low risk women including multiparas being delivered at centers providing different levels of care under different standards and with presumed differences regarding elective IOL at term. 
Our finding of a decreased rate of cesarean delivery and blood transfusion is consistent with a decreased risk for postpartum hemorrhage, puerperal infection, and uterine rupture, all risk factors for cesarean hysterectomy and ICU admission in the puerperium. This is important as previous work reported in the literature not only raised concerns with IOL at term and increased risk for cesarean delivery, but also reported complications directly related to the process of IOL ${ }^{30,31}$. Multiple studies have reported an increased risk for uterine rupture associated with cervical ripening agents and IOL but this is after a prior cesarean delivery ${ }^{32}$.

Our finding of lower risk for transfusion in the $\mathrm{IOL}$ group is reassuring but regrettably provides a limited assessment of the amount of blood loss at delivery and frequency of postpartum hemorrhage as this is not a variable reported in the live or stillbirth certificate. The data also does not allow us to gauge the severity of the intrapartum hemorrhage or the volume of blood transfused.

A novel finding of our study is the $23 \%$ increase of the rate of cesarean hysterectomy in the induction of labor group. This new finding was identified as the large study population is powered to detect rare adverse outcomes. The increased rate of cesarean hysterectomy cannot be attributed to differences in the rates of uterine rupture or obstetrical hemorrhage, the two most common indications, as these were either not different or lower within the IOL group. Induction agents, such as prostaglandins and oxytocin, have also been associated with risk for uterine atony and rupture; however, we were unable to determine what agents were used for $\mathrm{IOL}^{30-34}$. Due to the nature of this study, the indication for cesarean hysterectomy could not be determined in this cohort, however, the overall rate was lower $(0.01 \%)$ than recent rates reported with induction of labor among nulliparous women undergoing $\mathrm{IOL}(0.11 \%)$ and history of cesarean delivery ${ }^{33}$. Factors associated with risk for cesarean hysterectomy include high parity, maternal age, previous cesarean delivery, placental pathology, uterine atony and uterine rupture ${ }^{34}$. We have demonstrated that the risk for cesarean and transfusion was lower in the IOL group, and although parity was higher in the IOL group, it also included a higher proportion of nulliparous women. Any effect from BMI was controlled for in the multivariate regression analysis. Although cause for uterine rupture is multifactorial, the factors that led to the increased risk will require future analysis, especially for factors that we were unable to analyze, including methods used for cervical ripening and induction of labor, duration of labor, and indications for cesarean delivery.

From a fetal and neonatal perspective, our data demonstrated that IOL at 39 weeks of gestation resulted in a significantly lower frequency of 5-minute Apgar $\leq 3$, requirement for ventilation, seizures or NICU admission compared with the expectant management group. Additionally, expectant management was not associated with an increase in the risk of fetal or neonatal deaths up to 28 days after delivery even when comparing progressively later weeks to 39 weeks. This is in contrast to what was seen with neonatal seizures and cesarean delivery, which had progressively higher rates and relative risks with each additional week of gestation.

\section{Strengths \& Limitations}


The strength of the current study is the heterogeneous nature and large sample size of pregnancies analyzed in both the elective IOL at 39 weeks of gestation group and the expectant management group. It was important to include fetal deaths that occurred during IOL of labor at 39 weeks in order to compare with the risk for fetal death with expectant management. We were able to do this by using the variable that is included in the certificate of fetal death describing the timing at which the death occurred although not reported consistently for all jurisdictions. Underreporting of intrapartum deaths would lead to a lower estimate of risk in the IOL group and overestimation of risk in the expectantly managed group where all fetal deaths are counted. An additional strength of this study is the quality of the data. The data collected and analyzed is based on birth certificate and fetal death certificate data. Although the quality of the data especially that related to gestational age has been questioned, the current use of the best obstetrical estimate of gestational age has validated this as a reliable variable ${ }^{35}$. We were also able to adjust the relative risks and include clinically relevant confounders.

Limitations of this study include the inability to review the indications for induction of labor, methods utilized for induction of labor, Bishop score, fetal monitoring, severity of bleeding requiring transfusion, severity of uterine rupture versus dehiscence, and/or indications for intervention such as cesarean delivery. However, it is assumed there is enough similarity in practice recommended by the American College of Obstetrics and Gynecology that this would not directly affect the data collected. Previous evaluation of the validity of this data supports it as reliable with a high degree of completeness and accuracy ${ }^{29}$.

\section{Interpretation}

The decision to proceed with elective induction of labor at 39 weeks is highly dependent on several factors among which the most important are adequate dating and calculation of the estimated date of delivery. In settings where this is not reliably determined, planning IOL can be associated with complications related to late preterm and early term delivery ${ }^{36}$. Dating relies on the last menstrual period and first trimester ultrasound ${ }^{36}$. When discrepancies occur ultrasound dating is used with varying degrees of uncertainty depending on the gestational age at which it is performed ${ }^{36}$. Implementing a standardized strategy for IOL is indispensable to avoid complications that have been reported in association with injudicious use of oxytocin or other cervical ripening agent ${ }^{37,38}$. The majority of IOL procedures occur in a hospital setting requiring adequate infrastructure and healthcare provider support to be performed safely ${ }^{38}$. After initiating IOL, fetal surveillance is an imperative, and standardized interpretation and response to abnormal fetal heart rate patterns are needed to avoid unnecessary interventions and the increased cesarean delivery rates reported in earlier studies ${ }^{37-39}$. Currently approximately $25 \%$ of pregnancies undergo elective IOL at various gestational ages ${ }^{38}$. As the majority of pregnancies deliver at a modal gestational age of 39 weeks, elective IOL would not necessarily be required for all women, but a standard of care emphasizing IOL at 39 weeks would lead to a significant increase of these procedures with their associated costs related to the interventions listed above ${ }^{40-43}$. Furthermore, it is concerning that resources allocated to IOL would decrease those available to care for 
high risk women as well as for those having a SOL. This concern may be misleading because they compare IOL to SOL ${ }^{14}$. The observed decrease in the cesarean section rates and improved perinatal outcomes would most likely be associated with decreased short and long-term costs. Even if short-term costs were similar, the improved perinatal outcomes would justify the intervention ${ }^{40-43}$.

Our findings are consistent with the most recently published studies and meta-analysis regarding elective induction of labor at 39 weeks gestation versus expectant management included women of advanced maternal age in one study and nulliparous women in the recent randomized controlled trial $11,15,17-$ $19,42,44,45$. Primary outcomes in these reports include cesarean delivery rates as well as composite neonatal outcome. Their results indicated that induction of labor at 39 weeks did not result in an increased rate of cesarean delivery and reported no increase in the rate of adverse neonatal outcomes.

\section{Conclusions}

In conclusion, our study demonstrates that in low-risk women induction of labor at 39 weeks gestation is benefits maternal or neonatal outcomes with significantly lower frequencies of maternal and neonatal morbidity when compared to expectant management through 42 weeks. We have also shown in secondary analysis that the risk for both maternal and fetal complications increases with each additional week of gestation after 39 weeks. Based on our study and supported by a growing body of literature, clinical protocols aimed at the avoidance of IOL at 39 weeks gestation in low-risk women seems unwarranted. Discussions should address the significant improvement in maternal and perinatal outcomes. The finding of increased rate of cesarean hysterectomy should be further investigated, particularly those factors that may potentially contribute to this complication.

\section{Abbreviations}

IOL: Induction of labor

SOL: Spontaneous onset of labor

Triple l: Chorioamnionitis

NICU: Neonatal intensive care unit

aRR: Adjusted relative risk

$R R$ : Relative risk

$R C T$ : Randomized controlled trial

$\mathrm{NIH}$ : National Institutes of Health

NCHS: National Center for Health Statistics 
$C D C$ : Center for Disease Control and Prevention

BMI: Body mass index

STROBE: Strengthening the Reporting of Observational Studies

\section{Declarations}

\section{Ethics approval and consent to participate:}

This study is a national retrospective cohort analysis using data abstracted from the NCHS and CDC's Division of Vital Statistics database. The data is publicly available and de-identified; therefore, no patients were directly involved and no ethics board approval was required.

\section{Consent for publication:}

All contributing authors provided consent for publication.

\section{Availability of data and material:}

All data is publicly available from the webpage of the National Center for Health Statistics, a division of the CDC, and can be downloaded from https://www.cdc.gov/nchs/data_access/vitalstatsonline.htm

\section{Disclosures of interests:}

No conflicts of interest to declare.

\section{Funding:}

No funding was required or requested to carry out this research

\section{Contribution to Authorship:}

SC and RY planned the study and obtained the necessary data. All authors (SCB, RY, MD, JR, SC) contributed to the analysis of the data and interpretation of results. SCB drafted the manuscript and all other authors assisted with editing of the manuscript. All authors have accepted it in its final form.

\section{Acknowledgements:}


We would like to thank the National Center for Health Statistics (NCHS) and Centers for Disease Control and Prevention's (CDC) Division of Vital Statistics for the creation and maintenance of this freely accessible database.

\section{Disclosure}

The author(s) report no conflict of interest

\section{References}

1. Macer JA, Macer CL, Chan LS. Elective induction versus spontaneous labor: a retrospective study of complications and outcome. American journal of obstetrics and gynecology. 1992;166(6 Pt 1):16901696; discussion 1696-1697.

2. Maslow AS, Sweeny AL. Elective induction of labor as a risk factor for cesarean delivery among lowrisk women at term. Obstet Gynecol. 2000;95(6 Pt 1):917-922.

3. Cammu H, Martens G, Ruyssinck G, Amy JJ. Outcome after elective labor induction in nulliparous women: a matched cohort study. American journal of obstetrics and gynecology. 2002;186(2):240244.

4. Dunne C, Da Silva O, Schmidt G, Natale R. Outcomes of elective labour induction and elective caesarean section in low-risk pregnancies between 37 and 41 weeks' gestation. J Obstet Gynaecol Can. 2009;31(12):1124-1130.

5. Ehrenthal DB, Jiang X, Strobino DM. Labor induction and the risk of a cesarean delivery among nulliparous women at term. Obstet Gynecol. 2010;116(1):35-42.

6. Luthy DA, Malmgren JA, Zingheim RW. Cesarean delivery after elective induction in nulliparous women: the physician effect. American journal of obstetrics and gynecology. 2004;191(5):15111515.

7. Vardo JH, Thornburg LL, Glantz JC. Maternal and neonatal morbidity among nulliparous women undergoing elective induction of labor. The Journal of reproductive medicine. 2011;56(1-2):25-30.

8. Vrouenraets FP, Roumen FJ, Dehing CJ, van den Akker ES, Aarts MJ, Scheve EJ. Bishop score and risk of cesarean delivery after induction of labor in nulliparous women. Obstet Gynecol. 2005;105(4):690697.

9. Osmundson SS, Ou-Yang RJ, Grobman WA. Elective induction compared with expectant management in nulliparous women with a favorable cervix. Obstet Gynecol. 2010;116(3):601-605.

10. Stock SJ, Ferguson E, Duffy A, Ford I, Chalmers J, Norman JE. Outcomes of elective induction of labour compared with expectant management: population based study. Bmj. 2012;344:e2838. 
11. Cheng YW, Kaimal AJ, Snowden JM, Nicholson JM, Caughey AB. Induction of labor compared to expectant management in low-risk women and associated perinatal outcomes. American journal of obstetrics and gynecology. 2012;207(6):502.e501-508.

12. Darney BG, Snowden JM, Cheng YW, et al. Elective induction of labor at term compared with expectant management: maternal and neonatal outcomes. Obstet Gynecol. 2013;122(4):761-769.

13. Mishanina E, Rogozinska E, Thatthi T, Uddin-Khan R, Khan KS, Meads C. Use of labour induction and risk of cesarean delivery: a systematic review and meta-analysis. CMAJ : Canadian Medical Association journal = journal de l'Association medicale canadienne. 2014;186(9):665-673.

14. Grobman WA, Caughey AB. Elective induction of labor at 39 weeks compared with expectant management: a meta-analysis of cohort studies. American journal of obstetrics and gynecology. 2019;221(4):304-310.

15. Middleton P, Shepherd E, Morris J, Crowther CA, Gomersall JC. Induction of labour at or beyond 37 weeks' gestation. Cochrane Database Syst Rev. 2020;7(7):Cd004945.

16. Saccone G, Della Corte L, Maruotti GM, et al. Induction of labor at full-term in pregnant women with uncomplicated singleton pregnancy: A systematic review and meta-analysis of randomized trials. Acta obstetricia et gynecologica Scandinavica. 2019;98(8):958-966.

17. Grobman WA, Rice MM, Reddy UM, et al. Labor Induction versus Expectant Management in Low-Risk Nulliparous Women. The New England journal of medicine. 2018;379(6):513-523.

18. Sotiriadis A, Petousis S, Thilaganathan B, et al. Maternal and perinatal outcomes after elective induction of labor at 39 weeks in uncomplicated singleton pregnancy: a meta-analysis. Ultrasound in obstetrics \& gynecology : the official journal of the International Society of Ultrasound in Obstetrics and Gynecology. 2019;53(1):26-35.

19. Society of Maternal Fetal Medicine. SMFM Statement on Elective Induction of Labor in Low-Risk Nulliparous Women at Term: the ARRIVE Trial. American journal of obstetrics and gynecology. 2019;221(1):B2-b4.

20. Park BY, Cryer A, Betoni J, et al. Outcomes of labor induction at 39 weeks in pregnancies with a prior cesarean delivery. The journal of maternal-fetal \& neonatal medicine : the official journal of the European Association of Perinatal Medicine, the Federation of Asia and Oceania Perinatal Societies, the International Society of Perinatal Obstet. 2020:1-6.

21. Walker KF, Bugg GJ, Macpherson M, et al. Randomized Trial of Labor Induction in Women 35 Years of Age or Older. The New England journal of medicine. 2016;374(9):813-822.

22. National Center for Health Statistics. 2021. https://www.cdc.gov/nchs/data_access/vitalstatsonline.htm. Accessed 02/02/2021.

23. American College of Obstetrics and Gynecology. ACOG Practice Bulletin No. 203: Chronic Hypertension in Pregnancy. Obstet Gynecol. 2019;133(1):e26-e50.

24. American College of Obstetricians and Gynecologists. Gestational Hypertension and Preeclampsia: ACOG Practice Bulletin, Number 222. Obstet Gynecol. 2020;135(6):e237-e260. 
25. American College of Obstetricians and Gynecologists. ACOG Practice Bulletin No. 201: Pregestational Diabetes Mellitus. Obstet Gynecol. 2018;132(6):e228-e248.

26. American College of Obstetricians and Gynecologists. ACOG Practice Bulletin No. 190: Gestational Diabetes Mellitus. Obstet Gynecol. 2018;131(2):e49-e64.

27. Elsmén E, Källén $K$, Marsál $K$, Hellström-Westas L. Fetal gender and gestational-age-related incidence of pre-eclampsia. Acta obstetricia et gynecologica Scandinavica. 2006;85(11):1285-1291.

28. McNutt LA, Wu C, Xue X, Hafner JP. Estimating the relative risk in cohort studies and clinical trials of common outcomes. American journal of epidemiology. 2003;157(10):940-943.

29. von Elm E, Altman DG, Egger M, Pocock SJ, Gøtzsche PC, Vandenbroucke JP. The Strengthening the Reporting of Observational Studies in Epidemiology (STROBE) Statement: guidelines for reporting observational studies. International journal of surgery (London, England). 2014;12(12):1495-1499.

30. Thisted DL, Mortensen LH, Krebs L. Uterine rupture without previous caesarean delivery: a population-based cohort study. European journal of obstetrics, gynecology, and reproductive biology. 2015;195:151-155.

31. Rydahl E, Eriksen L, Juhl M. Effects of induction of labor prior to post-term in low-risk pregnancies: a systematic review. JBI database of systematic reviews and implementation reports. 2019;17(2):170208.

32. Lydon-Rochelle M, Holt VL, Easterling TR, Martin DP. Risk of uterine rupture during labor among women with a prior cesarean delivery. The New England journal of medicine. 2001;345(1):3-8.

33. Sørbye IK, Oppegaard KS, Weeks A, Marsdal K, Jacobsen AF. Induction of labor and nulliparity: A nationwide clinical practice pilot evaluation. Acta obstetricia et gynecologica Scandinavica. 2020;99(12):1700-1709.

34. van den Akker T, Brobbel C, Dekkers OM, Bloemenkamp KWM. Prevalence, Indications, Risk Indicators, and Outcomes of Emergency Peripartum Hysterectomy Worldwide: A Systematic Review and Meta-analysis. Obstet Gynecol. 2016;128(6):1281-1294.

35. Martin JA, Hamilton BE, Osterman MJK, Driscoll AK. Births: Final Data for 2018. National vital statistics reports : from the Centers for Disease Control and Prevention, National Center for Health Statistics, National Vital Statistics System. 2019;68(13):1-47.

36. American College of Obstetricians and Gynecologists. Committee Opinion No 700: Methods for Estimating the Due Date. Obstet Gynecol. 2017;129(5):e150-e154.

37. Kernberg A, Caughey AB. Augmentation of Labor: A Review of Oxytocin Augmentation and Active Management of Labor. Obstetrics and gynecology clinics of North America. 2017;44(4):593-600.

38. Tsakiridis I, Mamopoulos A, Athanasiadis A, Dagklis T. Induction of Labor: An Overview of Guidelines. Obstetrical \& gynecological survey. 2020;75(1):61-72.

39. Association of Women's Health OaNN. Elective Induction of Labor. Nursing for women's health. 2019;23(2):177-179. 
40. Little SE. Elective Induction of Labor: What is the Impact? Obstetrics and gynecology clinics of North America. 2017;44(4):601-614.

41. Hersh AR, Skeith AE, Sargent JA, Caughey AB. Induction of labor at 39 weeks of gestation versus expectant management for low-risk nulliparous women: a cost-effectiveness analysis. American journal of obstetrics and gynecology. 2019;220(6):590.e591-590.e510.

42. Einerson BD, Nelson RE, Sandoval G, et al. Cost of Elective Labor Induction Compared With Expectant Management in Nulliparous Women. Obstet Gynecol. 2020;136(1):19-25.

43. Caughey AB, Sundaram V, Kaimal AJ, et al. Maternal and neonatal outcomes of elective induction of labor. Evidence report/technology assessment. 2009(176):1-257.

44. Souter V, Painter I, Sitcov K, Caughey AB. Maternal and newborn outcomes with elective induction of labor at term. American journal of obstetrics and gynecology. 2019;220(3):273.e271-273.e211.

45. Walker KF, Bugg G, Macpherson M, et al. Induction of labour versus expectant management for nulliparous women over 35 years of age: a multi-centre prospective, randomised controlled trial. $B M C$ pregnancy and childbirth. 2012;12:145.

\section{Figures}

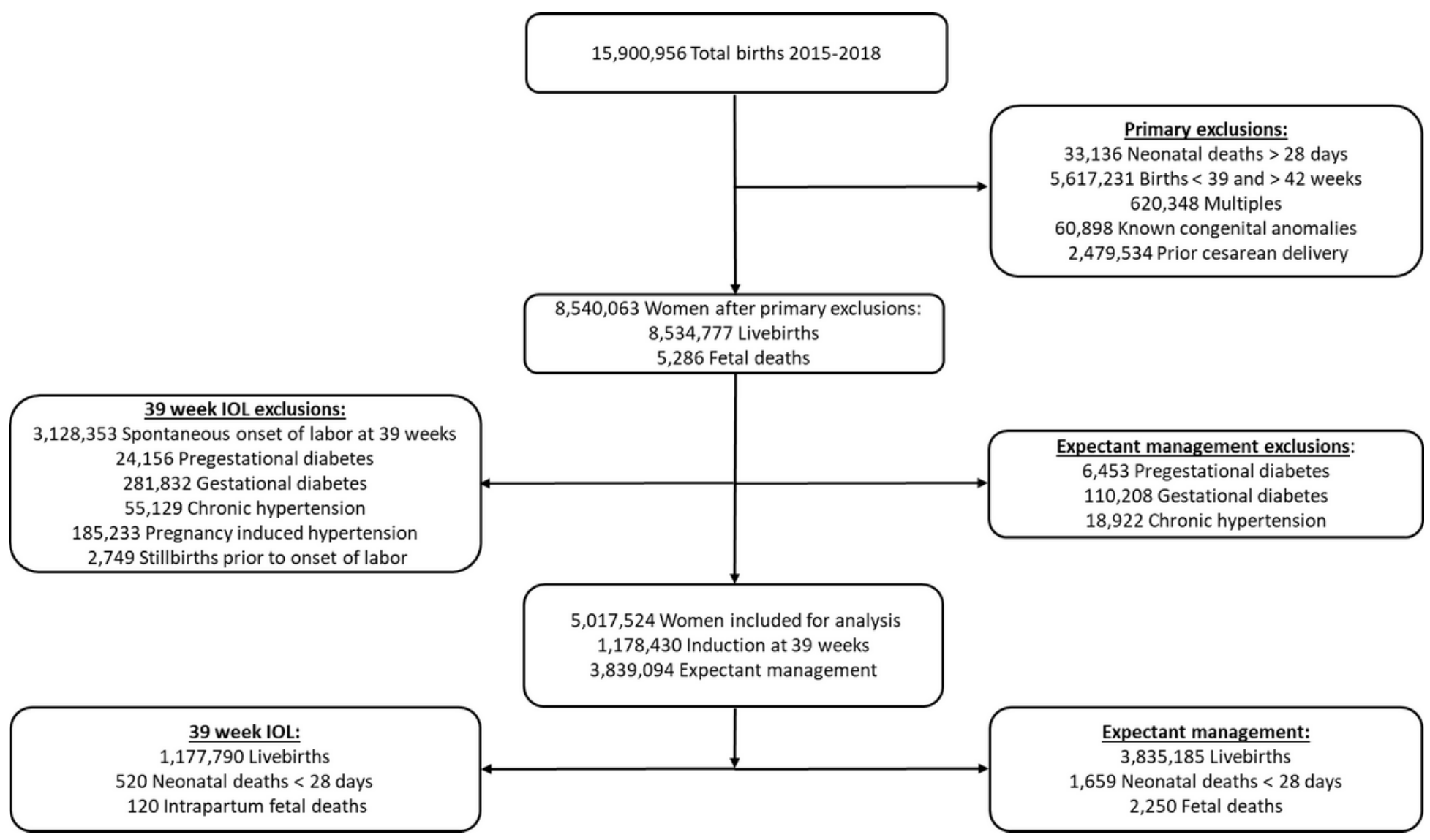

Figure 1

Flow diagram of the cohort selection from births and fetal deaths reported from 2015 to 2018 